EM

\title{
TERRA DE UM, TERRA DE VÁRIOS: INTERSECÇÕES ENTRE A TERRA DE NEGÓCIO E A TERRA DE TRABALHO EM PEQUIZEIRO - TO
}

\section{EARTH OF ONE, EARTH OF VARIOUS: INTERSECTIONS BETWEEN THE BUSINESS EARTH AND THE WORKING EARTH IN PEQUIZEIRO - TO}

\author{
Lázaro Wandson de Nazaré TELES ${ }^{1}$ \\ Roberto de Souza SANTOS ${ }^{2}$
}

\begin{abstract}
Resumo: O presente artigo é resultado de pesquisa teórica e empírica de dissertação de mestrado em Geografia. O objetivo da pesquisa é analisar o Assentamento Progresso no município de PequizeiroTO, como fração do território capitalista a partir das novas formas de produção e relações sociais de produção. O estudo está baseado a partir da análise do Plano de Desenvolvimento de AssentamentosPDA e de entrevistas aos assentados. O método utilizado foi o materialismo dialético para analisar as contradições sociais recorrentes no campo e o impacto da criação do Assentamento Progresso nas famílias assentadas. Os resultados apontaram que a criação do assentamento marcou a transição da terra de negócio para a terra de trabalho, mas que após 2002 apontou no caminho da produção de matéria-prima (o leite) para a indústria e, consequentemente, criou-se uma relação antes não estabelecida, já que, os excedentes tinham em seus destinos principalmente as feiras da região e ao consumo de subsistência. Agora, a relação é de subordinação da produção camponesa a indústria, e se trata de venda do leite para os laticínios.
\end{abstract}

Palavras-Chaves: Produção camponesa; Terra de trabalho; Terra de negócio; Assentamento.

\begin{abstract}
This article is the result of theoretical and empirical research of a Master's dissertation in Geography. The objective of the research is to analyze the Progresso Settlement in the municipality of Pequizeiro-TO, as a fraction of the capitalist territory from the new forms of production and social relations of production. The study is based on the analysis of the Settlement Development Plan-PDA and interviews with settlers. The method used was dialectical materialism to analyze the social contradictions recurring in the field and the impact of the creation of the Progresso Settlement on settled families. The results showed that the creation of the settlement marked the transition from business land to work land, but that after 2002 it pointed in the way of the production of raw material (milk) for industry and, consequently, a relationship was created previously not established, since the surpluses were mainly at the region's fairs and subsistence consumption. Now the relationship is one of subordination of peasant production to industry, it is the sale of milk for dairy products.
\end{abstract}

Keywords: Peasant production; Working land; Business land; Settlement.

\section{Introdução}

As ações de violência do capital sobre as populações amazônicas tiveram o aporte do Estado, principalmente durante o governo militar. Ianni (1978, p.158) discorre sobre o

\footnotetext{
${ }^{1}$ É Graduado em Geografia pela Universidade Federal do Tocantins (2008); Membro do Núcleo de Estudos Urbanos, Regionais e Agrários - NURBA/UFT; Mestre em Geografia pelo Programa de Pós-graduação em Geografia da Universidade Federal do Tocantins; e atualmente é professor do Instituto Federal de Educação, Ciência e Tecnologia do Pará e doutorando em Geografia pela USP. E-mail lazarogeo@ hotmail.com

${ }^{2}$ É professor do curso de Geografia e professor do Programa de Pós-graduação em Geografia no Campus Universitário de Porto Nacional -TO da UFT. Membro do Núcleo de Estudos Urbanos, Regionais e Agrários NURBA/UFT. Email robertosantos@uft.edu.br
} 
assunto, afirmando que "as tensões e os conflitos cresceram de envergadura e multiplicaramse em número, na mesma proporção que cresceu o afluxo de empresa e empresários para área em busca de terras boas para pastagens, lavoura e mineração ou extrativismo". O capital chega à região subsidiado pelos programas de fomento do Estado através dos órgãos governamentais como SUDAM, Banco da Amazônia, Banco do Brasil, Instituto Nacional de Colonização e Reforma Agrária - INCRA, e outras agencias do poder estatal de fomento para o capital.

A terra lócus de trabalho do camponês após a chegada do capital se transforma em mercadoria e é apropriada de forma privada e, essa apropriação ocorre de forma massiva, articulada e violenta. Observa-se que a ação do capital na apropriação e na expansão das propriedades privada das terras na Amazônia, é amparada pelo aparelho estatal e resulta no surgimento dos conflitos e violência, provocados pelos interesses antagônicos entre latifundiários, trabalhadores do campo e posseiros. Na medida em que ocorrem novos desenvolvimentos das relações capitalistas de produção na área, agravam e explodem as contradições entre os posseiros, os grileiros, indígenas e os fazendeiros. Contradições essas que envolvem várias modalidades de violência: tanto a violência privada, praticada pelos pistoleiros ou jagunços a mando de grileiros e fazendeiros, como a violência estatal legitimada e praticada por policiais ou outros segmentos do setor público.

As contradições em relação as frentes migratórias para a Amazônia se apresentam nos interesses e perfis dos sujeitos sociais envolvidos na disputa das terras. Com crescente aumento do latifúndio, como resultado do avanço do capitalismo no campo, amplia-se também o número de proletários no campo provocado pelas expropriações das terras dos camponeses, ou "pela atração de trabalhadores excedentes dos estados do Nordeste ou outras regiões do país", (IANNI 1978, p.235). Na região amazônica são esses trabalhadores que realizam todo o processo de ampliação e consolidação da atividade capitalista no campo, desde trabalho de derrubada, queimada da floresta, a formação de pastagens até a defesa da propriedade, como produção e reprodução do capital. São nos conflitos entre essas classes antagônicas, gerados pelos violentos processos de disputa pela posse da terra, que transforma a terra como local de vida e de trabalho em mercadoria. Transforma-se a terra de valor de uso em valor de mercado através da introdução e consolidação do capitalismo agrário, que se desenvolve na fronteira da Amazônia tocantinense.

Entretanto, Martins (1997, p. 147), afirma que "apesar da história de deslocamento da fronteira agrícola ser de destruição, é também uma história de resistência, de revolta, de 
protesto, de sonho e de esperança". Os sonhos e as esperanças de famílias que foram expropriadas de suas terras, somando aos de migrantes de outras regiões que viviam fora da lógica das frentes pioneiras e dos subsídios do Estado, se organizaram através de Sindicatos dos Trabalhadores e Trabalhadoras Rurais e apoiados por setores da igreja como a Comissão Pastoral da Terra - CPT. Estas entidades ajudaram e ajudam na organização política e na mobilização e ocupação de camponeses em fazendas da região. Tal postura política e estratégica destas entidades permitiu que ocorressem um importante processo de reocupação de terras no estado do Tocantins. Essas tentativas de (re) ocupações resultaram em acampamentos e, posteriormente, nas implantações de assentamentos que inauguraram um novo processo de territorialização da luta contra as grandes propriedades rurais.

Para analisar esta realidade em nosso objeto de estudo foram realizados trabalhos de campo e revisão bibliográfica. Os procedimentos metodológicos basearam-se no método qualitativo e em uma revisão bibliográfica sobre o debate teórico a respeito da relação entre a terra de trabalho e terra de negócio. Após o levantamento bibliográfico, procedeu-se a compilação, organização e interpretação dos dados e informações teóricas e empíricas, disponíveis na literatura adotada. Com este procedimento, o objetivo foi levantar uma discussão empírica e teórica para comparar e confrontar estes dois mundos diferentes (terra de negócio e terra de trabalho), masque formam uma unidade dialética social contraditória. Os procedimentos teórico-metodológicos foram organizados e estruturados a partir de uma análise teórico-crítica sobre o processo de apropriação da terra dentro do modelo de produção capitalista. A discussão teórico-metodológica procede de duas formas: um debate teórico a partir da interpretação do referencial bibliográfico utilizado e trabalhado e uma reflexão a partir das experiências e pesquisas acumuladas durante as pesquisas de mestrado.

O recorte analítico utilizado no desenvolvimento da reflexão compreende o município de Pequizeiro-TO, onde se estabeleceu a partir da reorganização do espaço agrário, por intermédio da transformação da terra de negócio para a terra de trabalho. O recorte espacial adotado para análise e pesquisa é do Assentamento Progresso no município de PequizeiroTO. A análise parte do pressuposto de que os fenômenos objetivados não se restringem à fronteira física da região, principalmente quando se trata de verificação e análise dos fenômenos geográficos pela sua complexidade. Em nossa análise, a escala é vista como uma estratégia de apreensão da realidade, que define o campo empírico da pesquisa, considerando que são os fenômenos que dão o sentido ao recorte espacial objetivado e também à categoria de análise. A análise geográfica dos fenômenos exige que a apreensão do espaço aconteça na 
escala em que ele é observado e compreendido, levando em conta que um espaço ou uma região possui uma dimensão territorial e uma dimensão social que interagem e configuram uma escala particular do espaço.

\section{Os assentamentos agrários: um caminho para terra de trabalho}

$\mathrm{Na}$ literatura, podemos encontrar a expressão assentamento rural ou assentamento agrário. No texto, usaremos o termo assentamento agrário. Segundo Brito (2013), o termo assentamento rural foi criado no âmbito das políticas públicas para nomear um determinado tipo de intervenção fundiária. $\mathrm{O}$ assentamento agrário pode ser entendido como um espaço, geograficamente delimitado, em que uma população será instalada por meio de políticas governamentais para realizar a sua exploração agrícola. A criação dos assentamentos está associada a conflitos, lutas populares e demandas sociais pelo direito de acesso à terra.O termo assentamento agrário está relacionado a uma gama de ações, tais como compra de terras, desapropriação de imóveis rurais ou mesmo utilização de terras públicas. As ações do Estado relacionadas à reforma agrária têm sido baseadas em políticas de criação de assentamentos agrários e concessão de crédito aos camponeses.

Essas intervenções visam a regulamentação de áreas ocupadas por posseiros e camponeses, afixação de segmentos de trabalhadores ameaçados de expulsão da terra e destinação de terras às populações que, desprovidas desse bem e organizadas pelo Movimento dos Trabalhadores Rurais Sem Terra, sindicatos ou outras entidades, pressionam o governo por meio da criação de acampamentos e ocupações de áreas para a realização de assentamentos agrários. Os assentamentos agrários, portanto, podem abranger diversos tipos de beneficiários diretos, como por exemplo, beneficia os posseiros, que, com longa história de permanência no campo, embora sem título formal de propriedade, podem ter a sua própria propriedade, a partir da criação de assentamentos. Os pequenos produtores, proprietários ou não, atingidos pela construção de hidrelétricas, seringueiros que resistem ao desmatamento que ameaça o seu modo de vida; assalariados rurais, muitas vezes completamente integrados no mercado de trabalho, populações de periferia urbana, também podem ter sua terra para trabalhar e produzir, se forem assentados em terras destinadas para reforma agrária (BRITO, 2013). 
Os assentamentos agrários são formados a partir do resultado de um longo processo de luta dos sujeitos sociais, que se encontram expropriados dos meios de produção e buscam se territorializar, e, assim, participarem da organização do espaço agrário. Estes sujeitos sociais lutam contra a forma de apropriação do espaço agrário determinada pelo modo de produção capitalista concentrador, ou seja, contra a grande propriedade privada. Segundo Bergamasco e Norder (1996), o termo assentamento começou a ser cunhado a partir dos anos 1960, pela população camponesa que vinha sendo expulsa do campo para os centros urbano, devido uma série de fatores como ausências de políticas públicas para o campo, incentivo do próprio estado para a migração para as cidades e a grilagem de terra. Os assentamentos agrários são entendidos por Bergamasco e Norder (1996) como novas unidades de produção agrícola, por meio de políticas governamentais visando o reordenamento do uso da terra, em benefício de trabalhadores rurais.

Segundo Souza (2018), o Incra define como Projeto de Assentamento um conjunto de unidades agrícolas independentes entre si, em que, originalmente, havia um imóvel rural pertencente a um único proprietário. São divididas em unidades chamadas de parcelas, lote ou gleba,que é entregue a uma família sem condições econômicas para adquirir ou manter um imóvel rural, por outras vias. Ainda segundo o Incra, o assentamento:

Consiste num conjunto de ações, em área destinada à reforma agrária, planejadas de natureza interdisciplinar e multisetorial integradas ao desenvolvimento territorial e regional, definidas com base em diagnósticos precisos acerca do público beneficiário e das áreas a serem trabalhadas, orientadas para utilização racional dos espaços físicos e dos recursos naturais existentes, objetivando a implementação dos sistemas de vivência e produção sustentáveis, na perspectiva do cumprimento da função social da terra e da promoção econômica, social e cultural do trabalhador rural e de seus familiares. (BRASIL, 2004, p. 148)

Essa definição do Incra, para nossa análise, é uma colocação vaga em relação ao assentamento, não pontuando a história de luta dos camponeses pela terra e, sobretudo, não explicita as contradições sociais da sociedade capitalista. Vale atermo-nos a função social da terra, de produção, um objetivo comum da terra de trabalho em que a reprodução camponesa ocorre. A realização dos assentamentos agrários é uma medida muito bem vinda para o camponês, no entanto, o ideal seria a criação de uma política de Estado de reforma agrária. Vale ressaltar que os assentamentos agrários são criados graças a organização e mobilização política do campesinato. Os assentamentos aparecem, ao longo dos anos, como a consagração da luta pela terra, desdobrando novas perspectivas de produção, renda, moradia e condições 
dignas de vida e de trabalho. Podendo ser especulado como um ponto de chegada, através do qual o acesso à terra permite a integração social, e como ponto de partida, em que os assentamentos se tornam novos territórios na produção familiar.

$\mathrm{Na}$ verdade, os assentamentos são frutos da contradição social pelo fato de a sociedade capitalista não oferecer os mesmos direitos aos camponeses, quilombolas, indígenas e ribeirinhos que são ofertados aos latifúndios e fazendeiros e ultimamente, ao agronegócio, inclusive. Aliás, mesmo perante as crises, o agronegócio continua ganhando dinheiro. Para que aconteça os assentamentos em um primeiro memento, há os acampamentos, que geralmente se localizam geograficamente, próximos a rodovias. Segundo Fernandes (2000, p.76), os acampamentos configuram-se em “(...) espaços e tempos de transição na luta pela terra (...)", pois, além de espaços de politização e socialização, criam pontos de tensão. São espaços dos conflitos e da luta pelo acesso à terra. A formação de assentamentos é uma consequência das lutas e mobilização política dos camponeses e trabalhadores sem-terra. Os governos e gestores públicos são pressionados a estabelecer políticas de reforma agrária. Em resumo, os assentamentos são projetos de assentamento criados pelas políticas de governos, porque no Brasil, não se tem uma política agrária de Estado.

Entretanto, uma coisa tem que ficar muito clara, sobre a postura do Estado em estabelecer políticas de criação de assentamentos agrários para os trabalhadores. Se analisarmos essa postura com mais atenção, iremos perceber que a criação de assentamentos por parte do Estado, não passa de uma estratégia política. Segundo Girardi e Fernandes (2008), a política de assentamentos agrários pode ser analisada como uma estratégia para não realizar uma reforma agrária ampla no país. A política de assentamentos agrários caracteriza, por seu alcance reduzido, a reforma agrária conservadora executada no Brasil. Essa política não consegue desconcentrar a terra, diminuir as desigualdades sociais ou impedir o êxodo rural, além de ter a Amazônia como válvula de escape para não reformar as regiões de ocupação consolidada no Centro-Sul e no Nordeste. Em resposta às ações dos movimentos sociais, os governos criam assentamentos agrários que, em princípio, constituem a conquista da terra.

Portanto, temos aqui, duas situações que precisam ser esclarecidas. Por um lado, estamos abordando que os assentamentos agrários são consequência das pressões dos movimentos sociais agrários sobre os governos e gestores públicos. Por outro, estamos afirmando que os assentamentos agrários constituem uma política estratégica do Estado em que se configura uma forma do poder público de continuar realizando políticas de 
assentamentos que não resolvem as questões sociais no campo, ao invés de estabelecer uma política de Estado de reforma agrária. Acreditamos que os dois raciocínios estão corretos, ou seja, os assentamentos significam uma nova etapa da luta: o processo pela conquista da terra e uma ação governamental quando se trata da desapropriação e formação jurídica do assentamento.Mesmo sendo assentado, o trabalhador precisa ainda conquistar condições de vida e produção na terra, resistir na terra e continuar lutando de maneira que permita o estabelecimento estável da agricultura camponesa continue existindo. O camponês precisa continuar resistindo em sua cultura, economia, formas de pensar e principalmente em sua terra. É uma luta contínua, a do campesinato. Ou seja, o caráter da luta de resistência de forma contínua tem dois momentos que são bem definidos na vida do camponês - a luta pela terra e a luta na terra.

Silva $(2005,142)$ diz que podemos chamar de movimento de luta na terra, o que denota uma fase posterior à luta pela terra. A luta pela terra é uma fase anterior em que o campesinato se mobiliza para adquirir um pedaço de chão. Já a (...) "luta na terra é uma expressão usada para significar que o camponês já se territorializou, garantiu o seu direito e o acesso à terra de trabalho, isto é, a seu espaço familiar produtivo...”. Significa a reação camponesa frente a expropriação e perversidade do Estado, do agronegócio e do latifúndio, isto é, o campesinato que quer continuar a ser camponês trabalhador - ser livre e autônomo. Ou seja, na vida pós-assentada do camponês continua sendo necessária sua luta pela sobrevivência.

O assentamento, com sua própria constituição, altera as relações de poder locais, pois, passa a atuar em área antes estabelecida como grande propriedade - a terra de negócio e que não cumpria a sua função social, promovendo uma mudança nas relações sociais de produção, anteriormente, estabelecidas. E com base na diversificação da produção, garantem assim a reprodução dos assentados. Para Fernandes (1996, p. 241), “a territorialização da luta pela terra é compreendida como o processo de conquistas de frações do território, e o assentamento como território é um trunfo na luta pela terra".

A regularização dos assentamentos pode proporcionar uma melhor distribuição da renda na agricultura passando necessariamente pela redistribuição da terra, permitindo que o assentamento, não seja mera formalidade, mas, acima de tudo, do poder da prosperidade e não do poder do atraso. A distribuição da terra de forma desigual, naturalmente, para o campesinato e para aqueles que precisam dela para sobreviver, fica desamparado. E enquanto o Estado não assume a sua responsabilidade social de instituir uma reforma agrária voltada as 
necessidades do camponês, o que resta-lhes são políticas de mitigação das desigualdades sociais no campo. Mas o que vemos é a apropriação de terras que faz dos latifundiários e capitalistas ligados a renda da terra, verdadeiros proprietários de imóveis em larga escala. Esses mecanismos fajutos de acesso à terra estão muito presentes na Amazônia, que direta ou indiretamente, desrespeita os direitos dos camponeses e atende aos interesses dos latifundiários e empresas do agronegócio.

Historicamente, os assentamentos agrários vêm se ampliando desde que o Movimento dos Trabalhadores Rurais Sem Terra atua na defesa do acesso à terra para os camponeses e trabalhadores do campo. No contexto da região da Amazônia, os assentamentos do INCRA na Amazônia continuam superando os das outras regiões.

Dos 8.200 assentamentos cadastrados no SIPRA até 31/12/2008, 3.019 são na Amazônia Legal, totalizando 655.325 lotes (do total de 1.012.471, ou $67,7 \%$ ) e 44,24 milhões de hectares (do total de 54,3 milhões, ou 81,4\%). Desde 2003, quase 64\% dos lotes abertos se localizam na Amazônia Legal e 55\% na Amazônia, sem o Estado do Maranhão, onde reside menos de 14\% da população rural brasileira. (TOURNEAU; BURSZTYN, 2010, p. 117).

Segundo Tourneau e Bursztyn (2010, p. 117 e 129), a evolução dos esforços de colonização na Amazônia levou o INCRA a criar diversas modalidades de assentamento. É uma (...) "tentativa de se adequar às circunstâncias e, mais recentemente, de se adaptar ao ambiente florestal e às crescentes preocupações a respeito do impacto ambiental dos seus projetos". Temos, assim, os assentamentos agrícolas considerados "clássicos",como os da categoria dos antigos Projetos Integrados de Colonização (PIC) e os Projetos de Assentamento Dirigidos (PAD) que se concentraram em Rondônia. Os lotes entregues eram maiores do que em outras áreas (até 250 ha) e os colonos deviam demonstrar uma competência agrícola, segundo o INCRA. O assentamento de sem-terras não era o objetivo dessa modalidade. Os Projetos de Assentamento Rápido (PAR) que tinham lotes de 25 a 50 ha, menores do que os PICs, foram instalados na continuidade dos projetos existentes.

Já sobre os atuais Projetos de Assentamento - PA, existem hoje os assentamentos agroextrativistas (Projetos de Assentamento Extrativista ou Agroextrativista - PAE), organizados a partir da Portaria INCRA n 627/1987 e 268/1996; os assentamentos agroflorestais (Pólos Agroflorestais - PE ou Projetos de Desenvolvimento Sustentável - PDS) definidos pela portaria do INCRA n 477/1999; e também formas descentralizadas, como os antigos Projetos de Assentamento Conjunto - PAC, em parceria com firmas privadas, e atualmente Projetos de Assentamento Casulo - PC, em parceria com as prefeituras. 
No Tocantins, Barbosa (2016) relata que de acordo com os dados oficiais do INCRA, os assentamentos agrários seguem uma classificação que está dividida em quatro modalidades: os assentamentos criados pelo governo estadual antes de 1988, que, após a esta data, passaram a ser reconhecidos pelo INCRA; os criados pelo programa de crédito fundiário; os criados e implantados pelo INCRA; e os reassentamentos de atingidos por barragens. Os assentamentos agrários criados pelo estado do Tocantins, reconhecidos pelo INCRA antes de 1988, já tinham sido implementados pelo governo de Goiás: cerca de 11 assentamentos que, após a criação do novo estado, foram reconhecidos pelo INCRA/MDA.

Os assentamentos considerados do Estado do Tocantins e posteriormente (1998 em diante) reconhecido pelo INCRA a partir de 1992 e 1997, são territórios camponeses, espacializados por 11 assentamentos ocupando uma área de 29.117 hectares, povoado por 271 famílias camponesas que residia e trabalhava no campo, lutando contra a pressão dos latifundiários que ameaçavam expropriarem de suas terras. (BARBOSA, 2016, p. 83):

Barbosa (2016, p. 84) coloca ainda que (...) “O reconhecimento de suas áreas como assentamento do INCRA, lhe garantiu mais segurança e esperança quanto à posse e o domínio da terra e o acesso a recursos públicos para assistência técnica e entre outros". Esse fato facilitou o processo de conquista da terra e do reconhecimento da luta camponesa da região, que por sinal, é marcada pela história de conflitos de terra na região do Bico do Papagaio tocantinense. Essas famílias ficaram concentradas na parte norte e no noroeste do estado do Tocantins.

Os assentamentos agrários criados a partir do Crédito Fundiário no estado do Tocantins são provenientes do programa implementado pelo Ministério do Desenvolvimento Agrário - MDA. Esse programa foi criado pelo governo federal na década de 1990 para garantir, aos camponeses, o acesso à terra por meio de financiamento-crédito junto aos bancos oficiais, destinados para compra de terras de propriedades privada. No estado do Tocantins esse processo iniciou-se a partir do ano de 2001, e sua forma de acesso à terra se dá por meio de três linhas de créditos-financiamento: Consolidação da Agricultura Familiar - CAF -, Banco da Terra - BT -, e Combate à Pobreza Rural - CPR (BARBOSA, 2016, p. 84-85).

Os assentamentos criados e implementados pelo INCRA no Tocantins estão distribuídos nas diversas formas de obtenção da terra, dentre elas, podemos destacar um total de 270 assentamentos criados por meio da desapropriação de terras consideradas pelos técnicos do órgão (INCRA) como improdutivas, passando assim a ser destinada para a Reforma Agrária. Outros 67 assentamentos foram criados através de arrecadação de terras 
públicas pertencentes ao estado e destinadas aos assentados; 16 assentamentos são provenientes de terras que foram adquiridas por meio de compra; 01 assentamento foi criado a partir da doação da propriedade para que fosse destinado ao processo de implantação; 01 assentamento foi implantado devido ao confisco do imóvel por parte da justiça e destinado ao processo de Reforma Agrária; 01 assentamento que foi proveniente de uma incorporação de uma área pública, totalizando 356 assentamentos criados e implantados pelo INCRA no Tocantins (BARBOSA, 2016, p. 80).

Segundo Barbosa (2016), os reassentamentos de atingidos por barragens são territórios camponeses, composto por sujeitos sociais que antes residiam em sua grande maioria próximo às margens dos rios, e que foram obrigados a se retirarem para outras localidades em função da construção de barragens para instalação de Usina Hidrelétrica, como a Usina do Lajeado, a Usina Hidrelétrica de Peixe e a Usina Hidrelétrica de São Salvador. As barragens das usinas hidrelétricas contribuíram para desabrigar mais de 356 famílias camponesas que foram reassentadas em 16 reassentamentos, distribuídas conforme as barragens das usinas hidrelétricas.

\begin{abstract}
A barragem da Usina Hidrelétrica de Lajeado contribuiu para desabrigar e reassentar 264 famílias em 11 reassentamentos, sendo 221 famílias foram reassentadas em 7 reassentamentos localizados no município de Porto Nacional-TO; 13 famílias foram reassentadas em 1 reassentamento localizado no município de Miracema do Tocantins; 4 famílias foram reassentadas em 1 reassentamento localizado no município de Lajeado; 6 famílias foram reassentadas em 1 reassentamento localizado no município de Ipueras-TO; 20 famílias foram reassentadas em 1 reassentamento localizado no município de Brejinho de Nazaré-TO. (BARBOSA, 2016, p. 84)
\end{abstract}

A formação destes reassentamentos segue uma lógica política que é a da negociação direta dos impactados pela construção das UHE e os consórcios construtores dos projetos. Cabe ressaltar que os reassentamentos de atingidos por barragens são territórios que foram ocupados por camponeses que perderam suas terras - a sua fonte de renda. Os assentamentos devem ser pensados como um grupo organizado e combatente, ou seja, os assentamentos devem ser locais de estratégias dos grupos que integram o campo de disputa em torno das demandas dos assentados para assegurar os direitos e interesses dos sujeitos sociais. No quadro 1, temos um resumo do número de assentamentos agrários criados no Tocantins entre 1987 e 2015. Neste quadro, podemos observar que o maior número de assentamentos são aqueles criados e implementados pelo INCRA. 
Quadro 1 - Assentamentos Implantados no Tocantins entre 1987 e 2015.

\begin{tabular}{|l|l|l|l|}
\hline Tipo de projeto & $\begin{array}{l}\text { Número de } \\
\text { assentamentos }\end{array}$ & $\begin{array}{l}\text { Quantidade de } \\
\text { famílias }\end{array}$ & $\begin{array}{l}\text { Área em } \\
\text { hectares }\end{array}$ \\
\hline $\begin{array}{l}\text { Os assentamentos criados pelo governo do } \\
\text { estadual antes de 1988, que após passaram a ser } \\
\text { reconhecidos pelo INCRA }\end{array}$ & 11 & 271 & 29.117 \\
\hline $\begin{array}{l}\text { Assentamento criado pelo programa de crédito } \\
\text { fundiário }\end{array}$ & 143 & 3.820 & 92.311 \\
\hline $\begin{array}{l}\text { Assentamentos criados e implantados pelo do } \\
\text { INCRA }\end{array}$ & 350 & 24.001 & 1.199 .750 \\
\hline Reassentamento dos Atingidos por Barragens & 23 & 356 & 15.624 \\
\hline TOTAL & 533 & 28.448 & 1.336 .802 \\
\hline
\end{tabular}

Fonte: Barbosa (2016, p.76).

\section{Assentamento Progresso: a terra de trabalho}

O Assentamento Progresso fica no município de Piquizeiro - TO. O Município de Pequizeiro está localizado no estado do Tocantins, entre as bacias hidrográficas dos rios Tocantins e Araguaia. O município surgiu após as descobertas de garimpos de cristal nas décadas de 1940 e 1950. Em 1944 existia na comunidade uma parada que era denominada Pousada de Pequizeiro, devido os viajantes usarem um alto e frondoso pé de pequi como ponto para espera de condução para dirigir-se a outras localidades, e assim deu-se a origem do nome do município. O povoado de Pequizeiro fazia parte integrante do município de Araguacema, e através da Lei Estadual n 4.595 de 1.963 (ainda sobre a tutela do Estado de Goiás) foi concedido sua autonomia e sua instalação ocorreu um ano depois. Após uma década e devido ao desenvolvimento de Colméia, que era distrito de Pequizeiro, a pedido de políticos e com a comprovação da evolução demográfica e econômica, a sede do município de Pequizeiro foi transferida para Colméia, através da Lei ${ }^{\circ} 8.809$ de 14 maio de 1.980 , no então estado de Goiás.

Pequizeiro, então, volta através dessa Lei à condição de distrito mantendo o mesmo nome. Com a Lei Estadual n 10.397 de 30 de dezembro 1.987, o distrito de Pequizeiro foi desmembrado de Colméia, sendo novamente elevado à condição de município, sendo instalado em $1^{\circ}$ junho de 1989 , já no recente criado estado do Tocantins. O município de Pequizeiro está localizado no Centro-Norte do estado do Tocantins, com proximidade do município de Conceição do Araguaia - PA, estando a uma altitude de 283 metros. O Mapa 1 demonstra a localização do município de Pequizeiro - $\mathrm{TO}^{3}$.

\footnotetext{
${ }^{3}$ Dados coletados IBGE -2017, na biblioteca do IBGE pelo site https://biblioteca.ibge.gov.br/visualizacao/dtbs/tocantins/pequizeiro.pdf
} 
Mapa 1 - Localização do Município de Pequizeiro no Estado do Tocantins.

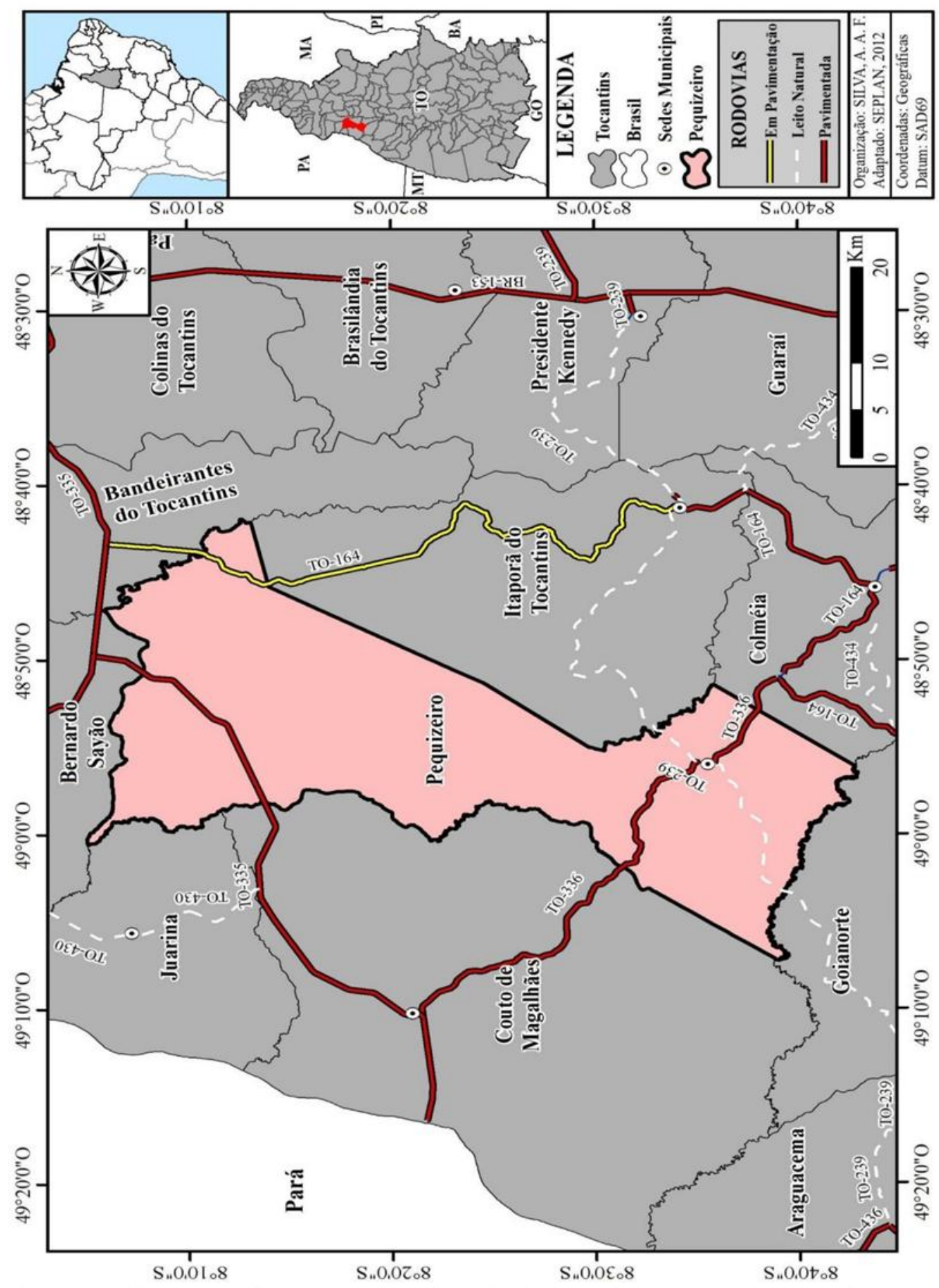

Fonte: Teles, (2013).

Ao longo de duas décadas, conforme demonstra a Tabela 01, houve a criação de nove assentamentos de Reforma Agrária no município de Pequizeiro que, em termos de área, representam 25.632,11 ha, o que já representa 21,2\% da extensão territorial do município. A efetivação destas unidades de produção no município de Pequizeiro tem favorecido o acesso à terra a cada vez mais pessoas que se encontravam distantes dos meios de produção, aqui, 
representados pela terra, essa que, por sua vez, se efetiva como instrumento de trabalho, e, portanto, terra de trabalho. Na Tabela 1, podemos observar que o Assentamento Progresso foi criado em 02 de março de 2000 e tem uma área de 6.784,5000 (ha).

Tabela 1-Projetos De Reforma Agrária Na Cidade De Pequizeiro - Tocantins.

\begin{tabular}{l|l|c|c|c}
\hline Nome do projeto & $\begin{array}{l}\text { Município } \\
\text { sede }\end{array}$ & Área (ha) & $\begin{array}{l}\text { Famílias } \\
\text { assentadas. }\end{array}$ & Data de criação \\
\hline PA Nossa S. Aparecida & Pequizeiro & $2.629,4400$ & 35 & $19 / 06 / 1996$ \\
PA Vitoria & Pequizeiro & $2.656,4500$ & 64 & $27 / 07 / 1999$ \\
PA Progresso & Pequizeiro & $6.784,5000$ & 186 & $02 / 03 / 2000$ \\
PA Conquista & Pequizeiro & $2.218,7998$ & 48 & $02 / 03 / 2000$ \\
PA Lontra & Pequizeiro & $1.608,8673$ & 31 & $02 / 032000$ \\
PA Cachoeirinha & Pequizeiro & 677,6000 & 17 & $21 / 08 / 2001$ \\
PA Mata Azul I & Pequizeiro & $4.287,0090$ & 101 & $09 / 05 / 2007$ \\
PA Pequizeiro & Pequizeiro & $1.163,5205$ & 25 & $22 / 12 / 2009$ \\
PA Província & Pequizeiro & $3.605,9237$ & 90 & $12 / 12 / 2011$ \\
\hline TOTAL & & $25.632,11$ & 596 & \\
\hline
\end{tabular}

Fonte: Instituto Nacional de Colonização e Reforma Agrária - INCRA, 2012. Adaptado pelo autor.

O Assentamento Progresso é uma área proveniente da Fazenda Monte Alegre. A ocupação da antiga Fazenda Monte Alegre iniciou-se em maio de 1996 com tensões, mas sem conflitos diretos, e contou com um grupo de aproximadamente 40 pessoas oriundas da cidade de Colinas do Tocantins. Nessa ocupação, os assentados se organizaram em Marcha da cidade de Colinas do Tocantins até a Fazenda Monte Alegre, o que dá em torno de $80 \mathrm{~km}$ de distância. A fazenda possuía, segundo, os assentados, entre 3.000 e 5.000 cabeças de gado e 3 vaqueiros responsáveis para cuidar do gado e outros que gerenciavam a fazenda.

Todos os entrevistados, ao descreverem o cenário da Fazenda Monte, colocam-na em um retrato de esquecimento e abandono, mesmo com os três vaqueiros responsáveis pelo gado. A terra, nesse cenário descrito, aparenta ganhar a forma de um instrumento, não de produção, mas de especulação, servindo, antes de tudo, para uma futura venda e obtenção da renda fundiária da terra. Nessa perspectiva, a terra ganha contornos de terra de negócio, aquela cujo capitalista se apropria com fins de apropriação do trabalho alheio, que era o que acontecia, já que na fazenda existiam trabalhadores assalariados. Ainda que, aparentemente aos olhos dos assentados, o proprietário da Fazenda Monte mostrasse certo desinteresse em relação a propriedade, já que, segundo eles, a "terra estava abandonada", lembramos que é um abandono aparente, pois na terra de negócio "serve para explorar o trabalho de quem não tem terra; ou serve para ser vendida por alto preço a quem dela precisa para trabalhar e não a tem" (MARTINS, 1980, p. 60).

As famílias que, antes, formavam um grupo de 40 que retornam a fazenda, no final do ano de 1996, era um grupo de aproximadamente 100 famílias. Percebe-se que a luta ganha 
força e o trunfo pela terra torna-se cada vez mais concreto aos olhos do camponês desprovido de seu principal instrumento de trabalho, a terra. Nesse período foram abertas estradas de acesso a fazenda e na área começou a ser implantadas lavouras de arroz, milho, feijão, fava, batata e cana-de-açúcar, constituindo, assim, a agricultura camponesa - a terra de trabalho. Como o processo de desapropriação perdurou até meados de 2000, mesmo sem conflitos diretos, o clima ainda era tenso, e, por isso, os trabalhos dos camponeses eram realizados em grupos, na tentativa de coibir qualquer tipo de agressão por parte dos funcionários da Fazenda Monte Alegre. Vale ressaltar que o excedente da produção camponesa era comercializado, principalmente, nos municípios de Colinas, Araguaína, Juarina e no próprio município de Pequizeiro.

Em 1998, o INCRA realizou a vistoria e acompanhou a retirada do gado da fazenda. Com isso, houve aumento da área plantada de lavoura sem alteração das culturas. Nesse período, receberam assistência técnica do Projeto Lumiar durante um ano. Já no ano de 1999, teve a peculiaridade de não haver produção em função da proibição do Instituto Brasileiro do Meio Ambiente e dos Recursos Naturais Renováveis - IBAMA de realizar queimada na área. A assistência técnica foi interrompida e, para que o sustento dos assentados fosse garantido, tiveram que alugar as terras para pastos, bem como, começaram a trabalhar por diárias em outras fazendas da região.

Nas maiores dificuldades de produção na época do acampamento, que perduraram por 4 anos até a criação do assentamento, chama-se atenção a do ano de 1999, foi quando os acampados foram proibidos pelo IBAMA de desenvolverem atividades na Fazenda Monte Alegre. Essa medida acabou gerando uma crise na produção e fornecimento de alimentos no acampamento, o que acabou forçando os acampados venderem sua força de trabalho em fazendas da região. Já no ano de 2000, houve a criação do assentamento e com isso, o sonho da terra se torna uma realidade, mas uma realidade ainda, longe do ideal como apontava os assentados. A partir daí, começou novamente a produção de diversas culturas no assentamento, mas, os assentados ainda não contavam com algum tipo de crédito ou assistência técnica mais incisiva em relação à produção.

Por volta de 2002, o Programa Nacional de Fortalecimento da Agricultura Familiar PRONAF é liberado para as famílias, criando assim condições para que os assentados pudessem organizar e estruturar suas culturas. Segundo os assentados, a demora no fomento era uma das principais dificuldades enfrentadas por eles. Já em 2003, começam as primeiras construções das residências, já que até então, as casas eram de tábua, em sua maioria cobertas 
de palha. Foram construídas fossas assépticas, melhorando as questões sanitárias no Assentamento Progresso. Foi construído também um barracão conforme demonstra a Figura 1, que acabou se tornando a sede da Associação Chico Mendes.

Figura 1- Associação Chico Mendes, Assentamento Progresso, 2011.

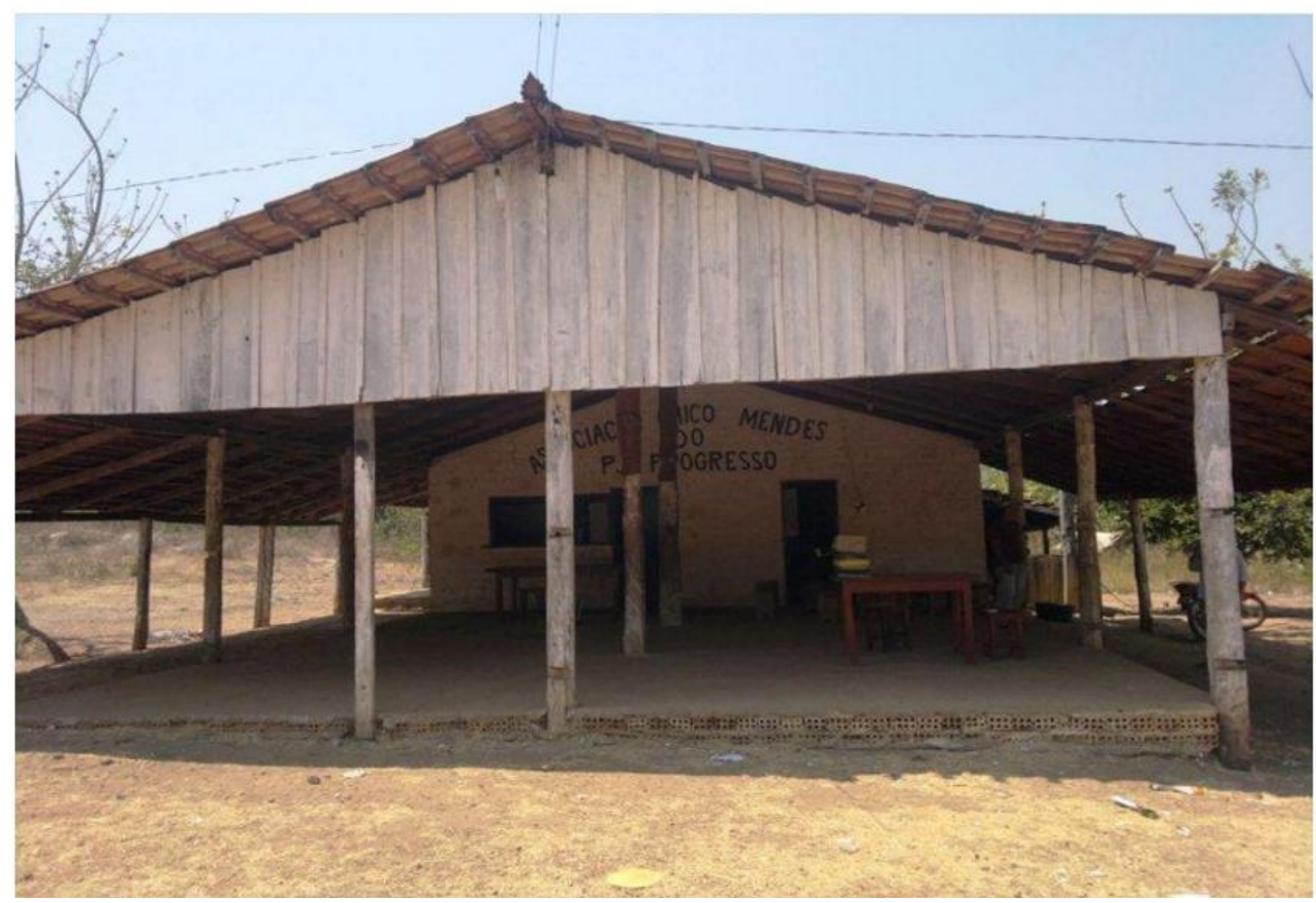

Fonte: Organizado pelo autor, 2013.

Foram quatro anos de luta, da marcha de 80 quilômetros, passando pelo isolamento da fazenda (na época) até às dificuldades de alimentação no acampamento. É neste contexto que surgem assentamentos rurais, entre dificuldade e esperança, fazendo-se por meio de um longo processo de luta de sujeitos que buscam a sua fração do território, e assim, participarem como sujeitos da terra-trabalho. Com a ocupação da então Fazenda Monte Alegre, em 1996, o latifúndio e a improdutividade cederam lugar à outra lógica, a terra enquanto negócio (de uma pessoa) deu lugar a terra de trabalho (dezenas de famílias), ou como o assentado J. F da S. coloca "Hoje eu sou o meu próprio patrão". Aqui, se faz menção às novas relações sociais de produção estabelecidas e a recusa a proletarização, pois se trata não mais de trabalho assalariado, mas de trabalho do tipo familiar. Inicia-se, portanto, o período de implantação das primeiras lavouras e consequentemente, surge a família, como motor da produção camponesa.

Essas mudanças corroboram para entendermos como seria essa outra lógica contrária a terra de negócio, afinal, na terra de trabalho não se vive na terra, mas sim, se vive a terra. É 
por isso, que nos cabe o papel de desmistificar o latifundiário como o sujeito responsável por toda a produção agropecuária no Brasil ou, como tendem a auto-intitularem, a locomotiva do desenvolvimento no Brasil. Neste sentido as palavras de J. F. R. ao falar das mudanças ocorridas com a criação do assentamento, nos ajudam a entender esse aspecto da produção brasileira:

Na época o proprietário da fazenda tinha cinco mil cabeças de gado na mão de uma pessoa só e hoje no assentamento existe duzentos e vinte seis famílias que moram dentro assentamento onde existe mais de nove mil cabeças de gados na mesma terra no mesmo local e por volta de seiscentas pessoas morando assentamento, além de aumentar a produção e o fazendeiro só produzia gado e hoje nós produzimos o arroz, o milho, o feijão, a batata, a banana, a mandioca, o peixe e derivados de leite; além de aumentar a produção dividiu a renda [...] a qualidade dentro do assentamento é outra.

A priori, cabe destacar que durante muito tempo se pensou que no assentamento havia 226 famílias, mas acontece que algumas famílias pertenciam a outro assentamento. Portanto, os números corrigidos dão conta de 186 famílias assentadas. Partindo dos dados dos assentados, podemos entender que uma fazenda de 6.784,500 ha, concentrados tão somente nas mãos de uma pessoa, deu lugar a uma nova forma de se organizar, bem como, de produzir: a produção na terra de trabalho em contraposição com o modo de produzir da terra de negócio.

A maior parte das atividades de pecuária do assentamento estava relacionada a criação de bovinos, geralmente, são raças cruzadas para fins de corte e leite. A produtividade é baixa, mesmo com a qualidade do pasto na região sendo boa. A produção agrícola era caracterizada por roça de toco de arroz, milho, feijão de arranque, mandioca e fava para subsistência, ou seja, em favor da sobrevivência do camponês e sua família. A roça de toco consiste na derrubada e queima da vegetação, após o início do período chuvoso segue-se um período de cultivo e que varia de 3 a 4 anos, após o declínio da fertilidade do solo, um período de pousio para restauração da fertilidade. Em algumas propriedades do assentamento, o objetivo da roça de toco seria a formação de pasto no primeiro ano, sendo necessária nova área no próximo ano.

As principais entidades representativas que as famílias estão vinculadas são a Associação Chico Mendes com $88 \%$ de associados, bem como, a Associação Analice Barros com $12 \%$ de associados. Durante a pesquisa de campo observamos que a Associação Chico Mendes possui atualmente, 173 associados,e a outra associação possui 13 associados. Isso 
aconteceu, já que, as pessoas dessa associação pertenciam a um grupo que foi assentado, posteriormente, e que por esse motivo preferiram fundar a sua própria associação.

Quanto a infraestrutura, o assentamento teve início sem uma estrutura mínima, que segundo os assentados não atendia as necessidades básicas de suas famílias. Assim, o início da instalação do assentamento foi marcado por uma série de dificuldades devido à ausência de serviços básicos. Os primeiros fomentos governamentais só foram instalados após dois anos da instalação efetiva do assentamento, no ano 2000. De acordo com o PDA, a infraestrutura inicial era a seguinte: energia: o Projeto de Assentamento não era servido por rede de energia elétrica, exceto onde funcionava a sede da fazenda; as estradas vicinais não existiam e o acesso era muito difícil, dificultando inclusive a escoamento da produção dos assentados; o assentamento não possuía qualquer tipo de infraestrutura em termos de saneamento básico, de modo que lixo, por exemplo, era queimado ou enterrado.

Havia uma escola que era de tábua e coberta de palha. Uma grande parte dos alunos estudava na Escola Família Agrícola - EFA, de Colinas do Tocantins e tem uma escola que funciona próxima à Associação Chico Mendes. Diferentemente do início do assentamento, hoje a escola é em alvenaria e telhado de barro. Além disso, o transporte escolar leva os alunos tanto para a escola do assentamento, como para escolas na sede do município de Pequizeiro. Ainda, constam alunos que estudam na Escola Família Agrícola - EFA da cidade de Colinas do Tocantins.

Todo o trabalho no sistema produtivo envolve toda a família (homens, mulheres e crianças), desde o plantio até a comercialização dos produtos. Quando necessário, contratavase terceiros em forma de diárias. As atividades de produção realizadas principalmente pelas famílias, sendo coletivamente ou ajuda mútua, era de queimadas e aceiros. Eventualmente, se fazia coletivamente, envolvendo um número menor de famílias, a aração, cova, capina e plantio. A produção destina-se ao consumo das famílias, sendo o excedente vendido na região para comerciantes, fazendeiros e atravessadores com pagamento de troca de produção por outros produtos.

Percebemos, aqui, alguns elementos estruturantes da produção camponesa como a força de trabalho familiar, que é o motor do processo de trabalho na unidade camponesa: a família camponesa é um verdadeiro trabalhador coletivo, a ajuda mútua entre os camponeses é a prática que eles empregam para suprir em determinados momentos. Entre essas práticas, está o mutirão ou a troca pura e simples de dias de trabalho entre eles. Esse processo aparece em função de os camponeses não disporem de rendimentos monetários necessários para pagar 
trabalhadores assalariados. Estas práticas representam a socialização do camponês que é um importante elemento da produção camponesa, pois, é através dela que as crianças são iniciadas, desde pequenas, como personagens da divisão social do trabalho no interior da unidade produtiva.

Entretanto, fora do assentamento, a realidade é outra, e quase todos os entrevistados sempre estiveram ligados a alguma atividade no campo, vendendo a sua força de trabalho em fazendas, trabalhando como meeiro em fazendas (dividindo a produção com o proprietário da terra) ou em pequenas posses dos pais, e uma minoria mesmo nascido no campo, exercia algum trabalho assalariado na cidade. Os entrevistados ressaltaram a respeito de nunca possuir o seu próprio pedaço de terra para produzir e, isso se constituía em um sonho, a conquista pelo seu pedaço de chão. Segundo o assentado L. A. “eu já plantava roça em arrendamento nas terras dos outros, fazia empreitas, consertava cercas". Portanto, tínhamos trabalhadores que pagavam renda para o uso da terra ou que vendiam a sua força de trabalho, mas, ainda viam distante o sonho de possuir sua própria terra. Antes mesmo do acampamento, uma entrevistada comenta o quanto é difícil não possuir o seu meio de produção "a terra". Ela (L. A.) diz "antes eu não tinha nada, nem família, só o dia para passar fome e a noite para sonhar, hoje tenho uma propriedade e família".

As coisas melhoraram no assentamento a partir do PRONAF e da Assistência Técnica, praticamente todas as famílias adquiriram gado para fins de corte e, principalmente, para a produção de leite. Durante pesquisas de campo em 2013, os presidentes da Associação Chico Mendes e da Cooperativa de Produção e Comercialização dos Agricultores Familiares de Pequizeiro e Região Ltda. - COOPERFAPER, afirmaram que em média, cada assentado já possuía 45 cabeças de gado, o que representaria um universo de 8.350 cabeças de gado em todo o Assentamento Progresso. Prova desse crescimento é o próprio torneio leiteiro, que em 2012já estava em sua quarta edição. Esse torneio, conforme demonstra a Figura 2, inclui cursos, sobre cadeias produtivas ou até mesmo sobre técnicas de aprimoramento na produção de leite de vaca. Os vencedores do torneio, geralmente, em um só dia retiram de uma vaca, em torno de 47 litros de leite, demonstrando que alguns assentados têm uma alta produtividade e uma relação cada vez mais forte com a indústria, já que, o destino final é o laticínio. 
Figura 2 - Torneio Leiteiro do Assentamento Progresso, 2012.

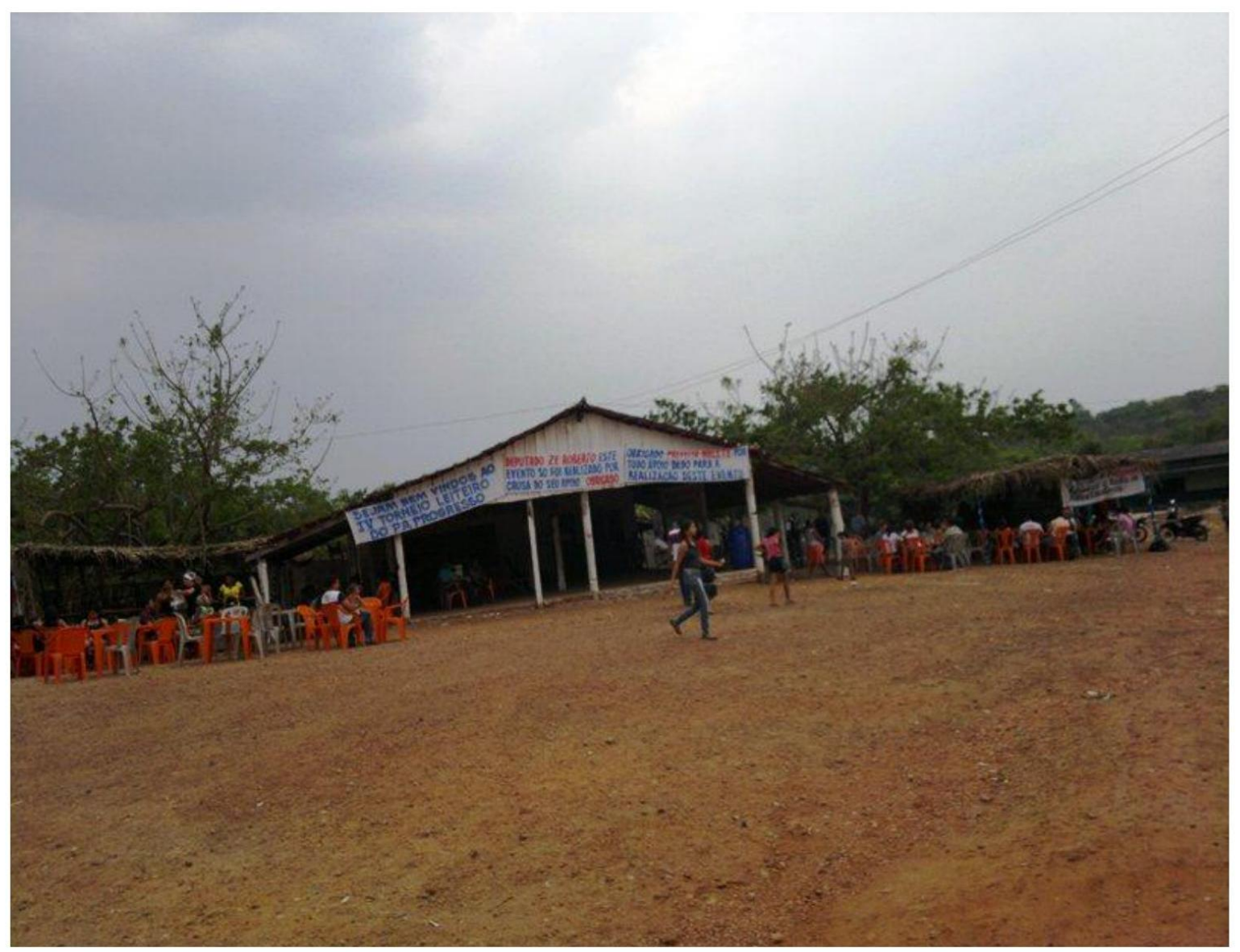

Fonte: Organizado pelo autor, 2013.

Nos últimos anos, todos os entrevistados tinham como atividade principal, a criação de gado e a produção de leite. Portanto, reprodução de outras atividades caiu drasticamente, mas isso não significa dizer que os assentados deixaram de produzir para a sobrevivência da família, e sim que deixaram de produzir excedente de outras produções. Para muitos assentados, o gado representa uma espécie de "poupança" para eventuais circunstâncias, pois, em caso de necessidade, a venda se apresenta como uma forma rápida de se converter a mercadoria em dinheiro. Para reforçar este raciocínio, um assentado J. F. R. afirma-nos que "gado pra mim é uma forma de poupança, em caso de necessidade a venda é rápida". A figura 3 mostra uma propriedade onde temos uma pequena produção de hortaliças para o consumo da família (Figura A); plantação de bananas, as quais, o excedente é vendido na cidade de Colinas do Tocantins (Figura B) e, a criação do gado para a produção do leite (Figura C). Constatamos ainda que nas propriedades há criação de galinhas e porcos para o consumo familiar. 
Figura 3 - Produção Familiar: Plantação de Hortaliças para o Consumo da Família (A); Plantação de Bananas para o Consumo e Venda do Excedente (B); Criação de Gado para a Produção de Leite (C).
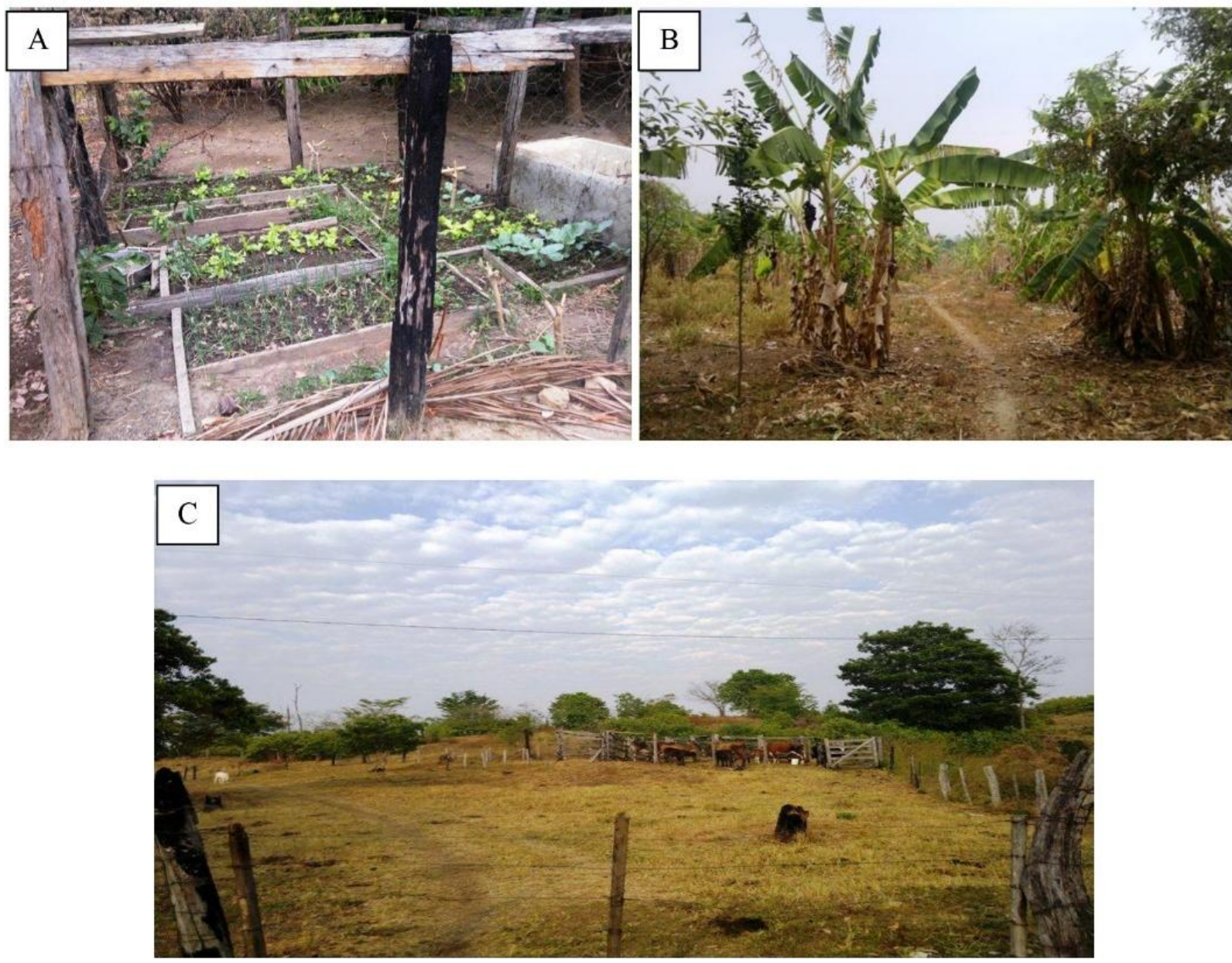

Fonte: organizado pelo autor, 2012.

Parcela da produção de leite do assentamento passou ser vendida para a indústria de laticínio. Sabemos que essa relação dos camponeses e trabalhadores com a indústria é uma relação de subordinação dos camponeses com a indústria. A partir dessa relação, a indústria passa a definir preços de acordo com os seus critérios de qualidade e exigir dos produtores assentados, padrão de qualidade que eles não estariam a altura de cumprir. Outro fator de exclusão dos camponeses produtores de leite é o pagamento diferenciado pela qualidade do leite, o que constitui em instrumentos para impor ao produtor a se especializar para produzir cada vez mais. Estes mecanismos configuram-se como instrumento para ampliar as amarras e subordinar a produção camponesa aos ditames da indústria capitalista.

A produção no assentamento era bastante diversificada, mas, a partir da relação dos camponeses com a indústria de laticínio, as famílias foram cada vez mais substituindo as áreas de cultivos por paisagens nítidas de formação de pastagem. Assim, gradativamente ao 
longo de 15 anos, a agricultura foi perdendo espaço para pecuária de leite. A criação de gado, então, sobressairia cada vez mais em relação às diversas culturas, chegando ao ponto de se tornar de grande relevância econômica para as famílias assentadas. Acontece que, a partir do momento que os camponeses vão plantando aquilo que é de interesse da indústria, pode ocorrer, por exemplo, da indústria sair da região ou falir, e então os produtores ficam sem compradores para seu produto.E se cada vez mais eles se especializam na produção de leite, vai faltar o arroz, a mandioca, o milho e etc. porque agora eles estão produzindo apenas o leite. É a terra de trabalho sendo subordinado aos interesses da terra do negócio.

Em entrevista, o presidente da Cooperativa de Produção e Comercialização dos Agricultores Familiares de Pequizeiro e Região Ltda. - COOPEFAPER (que integra os diversos assentamentos do município de Pequizeiro), afirmou que: “O preço (do leite) deveria variar de acordo com o período de chuva e seca, mas nem isso está ocorrendo mais. Acho também, que o preço pago pelos laticínios não é justo, pois os produtos industrializados são caros. É por isso que poderíamos ter mais domínio sobre o preço de nossa produção”, (J. A. C.). Segundo o assentado, fazendo os cálculos, tirando custos com a produção como vacina, alimentação e eventuais cuidados com o gado, o litro do leite lhe renderia aproximadamente $\mathrm{R} \$ 0,03$ centavos, tornando-se, em muitos casos, uma produção inviável, onde os assentados acabam se tornando reféns da indústria.

Ainda em relação aos preços praticados pelos laticínios, o presidente da Associação do Assentamento (Associação Chico Mendes) coloca o seguinte:

"Se a gente for colocar no bico da caneta, as vezes a gente nem tira leite, porque a gente tem gastos com a criação da hora que ele nasce até a data que você estiver desleitando ela, então isso, se for colocado, você nem tira leite, e o preço do leite, quem coloca são eles, não é a gente", (Entrevista com A. P. de O. realizada pelo autor, em março de 2012).

Os valores pagos pelos laticínios por litro de leite, durante as nossas pesquisas de campo, variaram de $\mathrm{R} \$ 0,48$ a $\mathrm{R}$ \$ 0,60 centavos, com pouca variação entre meses de chuva e seca. Entretanto, os produtos se mostraram estáveis, pelo menos nos supermercados. Ou seja, quando o produto do camponês está sob o seu domínio, o preço é um, mas quando este mesmo produto entra no ambiente regrado pelos capitalistas, o seu preço é totalmente diferente.

Portanto, a questão do preço coloca o assentado numa situação complicada, já que, quanto maior for a exploração do capital sobre a unidade camponesa, maior será a transferência de renda para o capital (nesse caso o laticínio). Nessa relação de sujeição da 
produção camponesa a indústria, como está posto, só quem ganha é a indústria. A maioria dos entrevistados respondeu que trabalha e vende o leite para manter o gado, pois, os preços estipulados pelos laticínios inibem qualquer tentativa de obterem um maior controle sobre a produção, bem como, a livre escolha de fornecer sua matéria-prima a quem quer que seja.

\section{Considerações finais}

O campo brasileiro aos olhos de grande parte de nossa população, é visto e aceito como um mero produtor de mercadorias para serem consumidas nas cidades ou nos grandes centros, desprovido de qualquer relação socialmente contraditória. O exercício de pensar o campo como um universo de possibilidades e contradições é um desafio necessário. A partir desse exercício, seremos capazes de entender o campo como "campo de forças", de conflitos, de lutas e de uma longa história de injustiça contra aqueles que nunca possuíram ou foram retirados de suas terras. Sem que se pese a luta para entrar na terra, somos eivados de informações midiáticas que nos levam a pensar e tratar aqueles que estão nas fileiras desta luta como "invasores", de maneira pejorativa. Esse quadro tem sido recorrente no modo de pensar da opinião pública.

O termo invasão é muito usado nos meios de comunicação em sentido moralista e deturpado, que sempre pretende indicar uma ideia de crime. Estamos comentando sobre as ocupações territoriais efetuadas pelos movimentos sociais das mais diversas categorias. Podemos enumerar vários exemplos, destes movimentos. Dentre os quais podemos destacar os movimentos sociais urbanos que ocupam imóveis em função da falta de moradia e pela falta de abrigo para a toda a população. Os movimentos dos trabalhadores camponeses que ocupam imóveis considerados improdutivos ou de propriedade do poder público. Estes fenômenos são corriqueiros na sociedade capitalista. Acreditamos que a verdadeira invasão é quando as comunidades tradicionais e indígenas são ameaçadas pelo capital industrial ou pelo agronegócio que invadem as terras indígenas. A imprensa escrita, impressa e, sobretudo as emissoras de televisão do circuito comercial são os verdadeiros interlocutores em dizer e defender que os movimentos sociais não passam de um movimento político baseado na insubordinação as leis.

Para eles, os movimentos sociais não praticam ocupação, mas sim invasões. Um verdadeiro exemplo de invasão que podemos comentar é aquele sobre a monocultura de 
eucalipto que constitui um dos mecanismos de territorialização/invasão do capital nas áreas de cerrado. A chegada do capital do agronegócio no cerrado constrange a liberdade dos camponeses e indígenas, por várias razões. A primeira é porque o agronegócio é uma das atividades econômica que atua em grandes propriedades de terra, e isso significa que uma pessoa apenas terá grandes propriedades de terra, e concentra a terra, e dessa maneira, não vai sobrar terra para todos. A segunda é porque não oferece mão de obra para a população local. Terceira, porque toda sua produção não fica na região, é para exportar. Os seus produtores também não gastam suas fortunas na região. Quarta, porque para produzir é preciso desmatar quilômetros e quilômetros de floresta, mesmo com a tecnologia atualmente disponível e que permite maior produtividade em espaços cada vez menores, acontece o contrário, o capital deseja desmatar mais. O agronegócio beneficia poucos, sendo que a maioria sequer habita a região e que, exatamente por isso, não respeita os lugares, sua natureza e sua cultura, colocando em risco todo esse patrimônio natural e cultural.

Com a invasão do agrotóxico utilizado na monocultura, esse pode chegar à nascente dos córregos. É a contradição entre os interesses "dos de fora" e os "do lugar". A contradição entre os que estão de passagem e os que estão e vão ficar no lugar. Com a invasão do agronegócio na região amazônica, os problemas ambientais e sociais tendem aumentar. Os efeitos dos agrotóxicos são visíveis. Os agrotóxicos acabam causando o envenenamento dos animais. O problema das pragas nas lavouras mecanizadas também já chegou às roças de toco, ou seja, nas lavouras tradicionais para subsistência das comunidades tradicionais. Essa realidade nas terras de trabalho é muito diferente, não tem agrotóxico, o desmatamento é menor, a oferta de emprego é maior do que nas terras de negócio.

O problema da estrutura fundiária no Brasil é histórica e tem colocado em rota de colisão dois regimes de propriedades existentes. De um lado, a terra de negócio, que tem a terra como mercadoria fruto do trabalho realizado pelos trabalhadores e, do outro lado a terra de trabalho, aquela em que a família é a base do trabalho na terra, sendo dali, que tiram o seu sustento e em caso de excedente, vendem na tentativa de garantir outras mercadorias necessárias a sua produção e reprodução. Entender essa transição foi o que nos motivou a realizar essa pesquisa, e assim, nos apropriarmos de instrumentos teórico-metodológicos capazes de discutir a trajetória dos assentados, desde a Fazenda Monte Alegre até a criação do Assentamento Progresso.

Essa busca nos propiciou definir que a história se iniciou no próprio contexto em que cada agricultor se encontrava no campo, e que tomou força na formação do acampamento, 
quando ainda eram considerados "invasores". Em relação a essa trajetória, o assentado E. G.

D. diz "a gente era considerado invasor e hoje a gente já é aceito". Essa história de luta dos camponeses no campo tem sofrido várias investidas (dos latifundiários), na tentativa de desmobilizar essas lutas, tratando-os como “invasores". A história é bem diferente, afinal, são 500 anos de expropriação, exploração e grilagem de terra pelos latifundiários no Brasil.

Para uma grande parte dos assentados a criação do gado se coloca como uma alternativa para eventuais problemas que venham a surgir, portanto, um tipo de "poupança", pela rapidez que se converte em dinheiro. A venda do leite nesse caso se tornaria providencial para manter o gado e assim manter a "poupança". A efetivação da COOPPERFAPER seria um caminho para agregar valor ao leite produzido pelos assentados, além de livrar das amarras dos laticínios, mas, não foi o que aconteceu. Além dessas amarras do camponêsassentado em relação a indústria leiteira, a especialização da produção de leite, pode representar fragilidade de diante de uma eventual crise. Como alternativa, há um estímulo à policultura que se apresenta como um caminho viável para a reprodução do modo camponês na terra. Portanto, é nessa relação contraditória entre produção camponesa e indústria, que as relações capitalistas de produção criam condições para que o campesinato se crie e recrie. Mesmo presos às amarras dos laticínios, que exploram grande parte da renda camponesa, os assentados seguem combinando elementos de suas tradicionais produções, como também produzindo matéria prima para a indústria.

\section{Referências}

BARBOSA, Messias Vieira. Reforma agrária no Tocantins: uma análise da luta e conquista da terra a partir do assentamento Paulo freire I e II Rio dos Bois - TO. Programa de Pósgraduação em Geografia, Universidade Federal de Tocantins, Porto Nacional/TO, 2016. p.116. (Dissertação de Mestrado em Geografia Humana).

BERGAMASCO, Sonia M. e NORDER, Luis A. Coelho. O que são Assentamentos Rurais. São Paulo: Brasiliense, 1996. Coleção Primeiros Passos.

BRASIL. II Plano Nacional de Reforma Agrária: Paz, Produção e Qualidade de vida no meio rural. Ministério do Desenvolvimento Agrário. Brasília, 2005. Disponível em $<$ http://www.incra.gov.br/index.php/servicos/publicacoes/pnra-plano-nacional-dereformaagraria $>$. Acesso em 9 de set. 2012.

BRASIL. Ministério Do Desenvolvimento Agrário. Instituto Nacional De Colonização E Reforma Agrária. Instrução Normativa Incra n.15, de 30 de março de 2004. D.O.U, 65, seção 1, p. 148, 5 abr. de 2004. 
BRITO, Maria Natália Silva. A reforma agrária na Amazônia paraense: implicações do processo de interdição de assentamentos rurais na vida de camponeses do Município de Pacajá. Programa de Pós-graduação em Agriculturas Amazônicas, Núcleo de Ciências Agrárias e Desenvolvimento Rural, Universidade Federal do Pará, Belém - PA, 2013. p.154. (Dissertação de Mestrado em Agriculturas Familiares e Desenvolvimento Sustentável).

ENGELS, Friedrich. A origem da família, da propriedade privada e do Estado. Tradução José Silveira Paes. São Paulo: Global, 1984.

FERNANDES, Bernardo Mançano. Movimento social como categoria geográfica: Geografia, política e cidadania. Terra Livre. São Paulo, n. 15, p.59-85, 2000

FERNANDES, Bernardo Mançano. MST: formação e territorialização. São Paulo: Hucitec, 1996.

GIRARDI, Eduardo Paulon; FERNANDES, Bernardo Mançano. A luta pela terra e a política de assentamentos rurais no Brasil: a reforma agrária conservadora. AGRÁRIA, São Paulo, n. 8, p. 73-98, 2008.

GONÇALVES, Carlos Walter Porto. Amazônia, Amazônias. $3^{a}$ ed. São Paulo: Contexto, 2019.

IANNI, Octavio. A Luta pela terra. Petrópolis: Vozes, 1978.

IBGE - Instituto Brasileiro De Geografia e Estatística, 2017.Disponível em <https://biblioteca.ibge.gov.br/visualizacao/dtbs/tocantins/pequizeiro.pdf>.Acesso em $08 \mathrm{de}$ março de 2021.

MARTINS, José de Souza. Expropriação e Violência: A questão política no campo. São Paulo: Hucitec, 1980.

MARTINS, José de Souza. Fronteira: a degradação do outro nos confins do humano. São Paulo: Hucitec, 1997.

MARX, Karl; ENGELS, Friedrich. Manifesto Comunista. São Paulo: Boitempo Editorial, 2002.

OLIVEIRA, Ariovaldo Umbelino de. Amazônia: monopólio, expropriação e conflitos. 4ed. Campinas - SP: Papirus, 1993.

OLIVEIRA, Ariovaldo Umbelino. Integrar para não entregar: políticas públicas e Amazônia. Campinas: Papirus, 1991.

OLIVEIRA, Ariovaldo Umbelino. Modo de Produção Capitalista, Agricultura e Reforma Agrária. São Paulo: Labur Edições, 2007.

PESSÔA, Vera Lúcia Salazar; SANCHEZ, Miguel Cézar. Ação do Estado e as transformações agrárias no cerrado das zonas de Paracatu e Alto Paranaíba - MG. Boletim de Geografia Teorética-AGETEO,Rio Claro - SP, vol. 19, n. 37-38, -, 1989, p.68-79. 
PICOLI, Fiorelo. O capital e a devastação da Amazônia. São Paulo: Expressão Popular, 2006.

SILVA, Felipe Maia Guimarães da. Questão agrária e modernização no Brasil. Centro de Ciências Sociais Instituto de Estudos Sociais e Políticos, da Universidade do Estado do Rio de Janeiro. Rio de Janeiro, 2014.p.254(Tese de Doutorado em Sociologia)

SILVA, Silvio Simione da. Resistência camponesa e desenvolvimento agrário na Amazônia-Acreana. Programa de Pós-graduação em Geografia da Universidade Estadual de São Paulo, Presidente Prudente-SP, 2005.p.284. (Tese de Doutorado em Geografia: Desenvolvimento Regional e Planejamento Ambiental)

SOUZA, Aline Lessa de. Et al. Sustentabilidade ambiental na Amazônia e os assentamentos rurais. Revista EDUCAmazônia- Educação Sociedade e Meio Ambiente, ano 10, v. XX, Número 1, p. 36-54, janeiro-junho de 2018.

TELES, Lázaro Wandson De Nazaré. Da terra de negócio à terra de trabalho: um estudo noAssentamento Progresso, Pequizeiro - TO. 2013. 110. F. Dissertação (Mestrado em Geografia). Programa de Pós-graduação em Geografia, Universidade Federal de Tocantins. 2013

TOURNEAU, François-Michel Le; BURSZTYN, Marcel. Assentamentos rurais na Amazônia: contradições entre a política agrária e a política ambiental. Ambiente \& Sociedade, Campinas, v. XIII, n. 1, p. 111-130, janeiro-junho de 2010.

VILELA, Francy José Ferreira. O liberalismo político de John Locke. Revista Pandora Brasil. No 60,janeiro de 2014.

ZOIA, Alceu; PERIPOLLI, Odimar João. Terra de negócio versus terra de trabalho: a terra como um direito para além do aparato legal. Revista HISTEDBR On-line, Campinas, $\mathrm{n}^{\circ}$ 69, p. 255-266, setembro de 2016. 